\title{
Sistema Interamericano de Derechos Humanos: presente y futuro
}

José Miguel Insulza*

\begin{abstract}
I
La situación política de nuestro hemisferio presenta actualmente una evidente paradoja. Por una parte, la región exhibe con orgullo más de dos décadas de gobiernos elegidos democráticamente. Entre diciembre de 2005 y diciembre de 2006, se realizarán en las Américas trece elecciones presidenciales, a lo que debemos agregar las elecciones generales en países de régimen parlamentario, las elecciones de Congreso y otras. En ninguna de estas elecciones hemos observado irregularidades graves y, salvo el retiro de la oposición venezolana previo a la elección de Congreso de diciembre pasado, los candidatos y partidos derrotados han reconocido la victoria de sus oponentes.
\end{abstract}

Desde el punto de vista de la legitimidad de origen de las autoridades atravesamos, por lo tanto, por un período de desarrollo democrático sin precedentes. Sin embargo, por otra parte, diversos países han enfrentado recientemente crisis institucionales y sociales, y los propios cambios políticos normales que se producen en las elecciones de algunos países revelan una fuerte insatisfacción con los resultados logrados por los gobiernos democráticos. En 2005 nuevamente dos gobiernos (Bolivia y Ecuador) no concluyeron sus mandatos mientras el de Nicaragua atravesó por períodos de gran inestabilidad.

En suma, si la legitimidad de origen parece consolidada, la legitimidad de ejercicio parece mucho más cuestionada. Los latinoamericanos, nos dice la encuesta Latinobarómetro, siguen creyendo que la democracia es la mejor forma de gobierno, pero muchos de ellos no asignan a sus gobiernos el carácter de democráticos y menos de un tercio está satisfecho con su democracia.

Los tropiezos y dificultades por los que atraviesa el quehacer público en nuestra región tienen que ver con problemas no resueltos de pobreza, desigualdad, discriminación y buen gobierno, que, aunque no sean siempre responsabilidad de los gobiernos de turno, son síntoma inequívoco de la incapacidad de los sistemas de gobierno para responder a las crecientes demandas ciudadanas. El gran problema de la democracia de hoy es, por lo tanto, la gobernabilidad.

La gobernabilidad democrática depende fundamentalmente de tres factores: el respeto y protección de los derechos humanos; una equitativa distribución de las oportunidades de crecimiento y progreso social; y el ejercicio transparente y eficiente de la función gubernativa. En tal sentido, factores indispensables para la consolidación de la gobernabilidad
* Secretario General de la Organización de Estados Americanos.

Este comentario está disponible en: www.anuariocdh.uchile.cl 
1 En sentido amplio, además de la CIDH y la Corte, deben considerarse parte del Sistema

Interamericano, la Comisión Interamericana de Mujeres, el Instituto del Niño y el Instituto Indigenista, entre cuyas tareas está la protección de derechos en las áreas de su competencia y también el Instituto Interamericano de Derechos Humanos, creado por la Corte para el estudio y promoción de estos derechos. Este artículo sólo se refiere, sin embargo, a la Corte y la Comisión. democrática, tales como una efectiva protección de todos los derechos humanos, incluyendo los de naturaleza económica, social y cultural, un poder judicial independiente y una prensa libre y plural, requieren todavía ser sustancialmente fortalecidos; mientras los índices internacionales muestran serios problemas de transparencia en muchos países, y los niveles de pobreza siguen siendo inaceptables en una región que, sin ser la más pobre, es la más desigual del planeta. Sin embargo, muchos grupos tradicionalmente excluidos de los beneficios del desarrollo, no tienen acceso a participar efectivamente en la vida de los países que habitan a través de los canales formales y manifiestan sus frustraciones por vías alternativas.

Dentro de este panorama, la región presenta diversos desafíos en materia de derechos humanos, entre ellos cómo promover y proteger los derechos humanos de los habitantes de nuestro hemisferio frente a los problemas actuales de miseria y discriminación que afectan a millones de sus ciudadanos; cómo enfrentar las consecuencias de las violaciones masivas de derechos humanos durante décadas de dictaduras militares y guerras civiles del pasado; y, por último, el fortalecimiento y desarrollo de algunas áreas específicas de protección, entre ellas, el derecho a la libertad de expresión, los derechos de las personas privadas de libertad; los derechos económicos, sociales y culturales; los derechos de los niños, la discriminación de género, la discriminación contra los pueblos indígenas y los afrodescendientes y la protección de los defensores de derechos humanos.

\section{II}

Nuestra Organización está orgullosa de su Sistema Interamericano de protección a los derechos humanos. La Comisión Interamericana de Derechos Humanos (CIDH o Comisión), como órgano principal de la OEA, responsable de la promoción, observancia y protección de los derechos humanos en el hemisferio, ha cumplido y sigue cumpliendo funciones esenciales en el mantenimiento de nuestras democracias y la protección de nuestros habitantes. Durante más de cuarenta años de funcionamiento la Comisión ha demostrado su seriedad y efectividad en la protección de estos derechos en el hemisferio. A ella se agrega, con ya más de veinticinco años de actividad, la Corte Interamericana de Derechos Humanos, cuya jurisprudencia se ha ido haciendo cada vez más importante en el ámbito internacional. En conjunto ambos instrumentos forman la parte central de un sistema interamericano de derechos humanos admirado y respetado ${ }^{1}$.

Cada año son más los ciudadanos de América Latina y el Caribe que acuden a la Comisión y a la Corte. Ello no significa que la situación de los derechos humanos en la región haya empeorado, sino que el acceso de la gente común al sistema se ha hecho mayor. Esto es resultado de la mayor conciencia de los habitantes de la región acerca de sus derechos y la credibilidad que ha alcanzado nuestro sistema como última instancia de protección de derechos que los ciudadanos creen vulnerados. Estos 
dos factores positivos ponen una nueva presión sobre la necesidad de ampliar y universalizar el sistema interamericano de derechos humanos para responder, precisamente, a las expectativas que los latinoamericanos depositan en él.

Sin duda, la independencia de la Comisión Interamericana y de la Corte respecto de los Estados Miembros, manifestada tanto en las resoluciones del Consejo Permanente y la Asamblea General como en la práctica cotidiana, ha sido la principal razón para el prestigio de ambos órganos. Este prestigio también se fortalece por la composición de la Comisión y de la Corte, ambas elegidas por sus Estados Miembros, pero integradas por personas individuales que no responden a las instrucciones de sus electores. Esta independencia provoca ciertamente dificultades y críticas en casos particulares cuando la Corte dicta sentencias, o la Comisión emite opiniones, sea en casos particulares o en los informes acerca de la situación de los derechos humanos en los países con los cuales los Estados discrepan. Pero nunca ha sido esto motivo para incurrir en la tentación colectiva de cercenar la autonomía o las prerrogativas de la Corte o la Comisión.

Al respecto, es interesante comparar la composición y atribuciones de la Comisión Interamericana de Derechos Humanos con su homónima de Naciones Unidas. La Comisión de Naciones Unidas está compuesta por países miembros que son elegidos por sus pares y designan sus representantes, a los cuales puede cambiar para cada sesión. Con esta composición la Comisión debe adoptar resoluciones sobre la situación general de derechos humanos en países miembros. El resultado ha sido la politización y la pérdida de credibilidad de la Comisión, que recientemente ha debido ser modificada de manera esencial, al menos para evitar que países con un récord profundamente negativo lleguen a sentarse en la Comisión.

La CIDH podría probablemente extenderse más a evaluaciones regulares de la situación en los países, además del tratamiento de casos individuales, en los cuales la Corte tiene también una creciente participación. Pero es significativamente más confiable en sus decisiones que en el caso de Naciones Unidas, lo cual muestra que es necesario mantener a toda costa una autonomía real, de manera no limitada, como la única forma de tener efectividad y credibilidad en un campo tan complejo y controversial como el de los derechos humanos.

III

La primera visita en terreno de la CIDH tuvo lugar en 1961, es decir, hace cuarenta y cinco años. En los treinta años que siguieron, la actividad de la Comisión se hizo mucho más frecuente y relevante cuando la violación de los derechos humanos se hizo más masiva como producto de las dictaduras de seguridad nacional del Cono Sur y de las guerras en Centroamérica, mientras, por otra parte, crecía en el mundo la atención por el respeto de los derechos humanos. 
Los primeros años de trabajo de la $\mathrm{CIDH}$ se caracterizaron por el afianzamiento del sistema interamericano de derechos humanos, ante desafíos como el de generar la conciencia de respeto por la democracia y las garantías fundamentales de toda persona. Tal vez uno de los principales valores del sistema es que surgió y se desarrolló confrontando las graves violaciones en que incurrían las aún numerosas dictaduras que existían en nuestro continente. Por muchos años, fue la CIDH el único refugio real frente a las tiranías y se hizo presente allí donde nadie lo hacía, desde el Cono Sur hasta Centroamérica.

Hace pocos días, por ejemplo, se recordaron los treinta años del golpe y la instalación de la dictadura militar en Argentina. El embajador de ese país ante la OEA realizó una amplia intervención sobre el tema ante el Consejo Permanente y, en una parte de su intervención, recordó como un hito importante la visita de la CIDH a Argentina en 1979. En ese año la dictadura todavía controlaba absolutamente el poder, las desapariciones eran frecuentes y se vivía aún un ambiente de total negación dentro del país, sólo desmentido por las manifestaciones de las Madres de Plaza de Mayo. Sin embargo, en ese ambiente la Comisión realizó su tarea; como lo hacía también en Chile y en otras dictaduras del Cono Sur, y luego en Centroamérica, donde en plena guerra los representantes de la Comisión viajaban a la región para conocer de la suerte de detenidos y desaparecidos.

Dado que esas dictaduras se sentaban a la mesa de decisiones de la OEA, es casi un milagro que la Comisión haya podido subsistir sin entorpecimientos graves de su gestión. Sin duda, parte importante tiene que ver con el apoyo irrestricto de otros gobiernos de la Organización, así como con la autonomía a toda prueba con que la Comisión realizaba su trabajo. A pesar de ello, suscrita la Convención Americana sobre Derechos Humanos en 1969, tardó casi diez años en reunir las once ratificaciones suficientes para entrar en vigor.

En la década más reciente, con el advenimiento de la democracia como el mejor y más deseable de los sistemas de gobierno para el desarrollo, la promoción y la protección de los derechos fundamentales, la preocupación fundamental del Sistema ha sido la de hacer justicia a los numerosos atropellos que constituyen la herencia del pasado. El aumento de la colaboración de los Estados Miembros con la CIDH a través de las últimas décadas ha hecho posible ampliar la efectividad de la protección de los derechos y libertades fundamentales y la obtención de justicia en incontables casos individuales. Al mismo tiempo, los informes que la Comisión presenta acerca de las realidades de países y sobre áreas especialmente sensibles, como la libertad de expresión, la discriminación de género o los derechos de los pueblos indígenas, han sido instrumentales en la elaboración de nuevos tratados, acuerdos y resoluciones del sistema interamericano en estas materias.

En los próximos años, el sistema de Derechos Humanos de la Organización enfrenta cuatro grandes desafíos, de los cuales dependerá en gran medida su capacidad para seguir respondiendo, como lo ha hecho 
hasta ahora, a las necesidades y expectativas de gobiernos y habitantes de América Latina y el Caribe. Estos desafíos son: la universalización de su jurisdicción, el acatamiento de sus resoluciones, la ampliación de sus funciones y el financiamiento de su actividad.

IV

1. Universalización: Si bien la Comisión Interamericana de Derechos Humanos es elegida por todos los miembros de la OEA y actúa a nombre de todos ellos, no ocurre lo mismo con la Corte Interamericana y con la Convención Americana sobre Derechos Humanos, aprobada en 1969, en vigor desde 1979 y ratificada hasta ahora sólo por veinticinco Estados (uno de los cuales la denunció en 1998). Ello significa que una parte importante del Sistema, incluyendo la Corte, no están hoy en vigor para diez países miembros, entre los cuales se hallan Canadá y Estados Unidos y ocho países del Caribe. Las razones para esta situación son diversas y van desde la compatibilidad de las disposiciones de la Convención con el derecho interno, hasta el temor de que la adhesión a la Convención signifique modificar normas sustantivas en materia de derechos de las personas o derechos reproductivos.

El sistema ha funcionado en esta situación y no puede decirse que la reticencia de algunos países para ratificar la Convención Americana haya constituido un factor inhabilitante. Pero mientras el Sistema Interamericano de Derechos Humanos no funcione en plenitud para todos los Estados Miembros, y sólo los países de América Latina y una minoría del Caribe sean parte de la Corte, la posibilidad de retrocesos siempre existirá y los países podrán intentar impedir el ejercicio de la jurisdicción contenciosa de la Corte, como lo hizo infructuosamente uno de los latinoamericanos en la década pasada o retirarse de la Convención, lo que sucedió con uno del Caribe en 1998, apenas alguna resolución les parezca dañina para sus intereses. Para el funcionamiento estable del sistema es necesario propender a una ratificación universal.

2. Cumplimiento: Ligado al problema anterior, pero con un impacto más inmediato en la actividad de la Corte y la Comisión, está el problema del cumplimiento de las resoluciones de estas dos instancias. La Comisión examina casos y formula recomendaciones a los Estados Miembros, para hacer justicia o reparar los daños incurridos con la violación de los derechos de las personas. La mayoría de ellos cumple siempre o casi siempre con las recomendaciones de la Comisión. Pero esta no es la generalidad de los casos; hay países que no las cumplen y ni siquiera responden a esas recomendaciones. Tampoco cumplen los Estados, a cabalidad, las sentencias de la Corte, aunque cuando ellas son jurídicamente vinculantes, ya que la Corte no tiene imperio en el ámbito nacional.

El déficit fundamental del incumplimiento se da en la obligación de hacer justicia, es decir, investigar, juzgar y castigar a los culpables. En muchos casos, los gobiernos declaran su voluntad de acatar la sentencia y de hecho sólo cumplen partes de ellas, especialmente en materia de 
reparación a las víctimas, pero no ocurre lo mismo con la obligación de hacer justicia. Las razones de ello van desde las dificultades creadas por el principio de "cosa juzgada" por parte de los Tribunales nacionales, a las dificultades políticas y prácticas de iniciar procesos.

No obstante, el incumplimiento de las resoluciones del sistema, sea en la Comisión o en la Corte, lo daña gravemente, tanto porque mantiene situaciones de impunidad que son endémicas en la región como porque deja abierta plenamente la puerta para que los países que cumplen puedan dejar de hacerlo en cualquier momento, argumentando las fallas de otros. Este asunto preocupa desde hace tiempo a la Corte y a la Comisión, que han desarrollado distintas actividades para incrementar el acatamiento a las decisiones. Pero, en definitiva, la cuestión del cumplimiento, esencial para el Sistema Interamericano de Derechos Humanos, es resorte de la voluntad de los países miembros y debe ser motivo de discusión y decisión política de ellos, si se quiere contar con un sistema plenamente operativo y efectivo en sus decisiones.

3. Ampliación: La gravedad de los hechos ocurridos en América Latina en las últimas décadas del siglo pasado condicionó en gran medida la actuación de nuestro sistema de derechos humanos. No podía ser de otra manera. Aún la Comisión y la Corte siguen llevando casos de violaciones del pasado, cometidas por regímenes ya extintos y por los cuales los actuales gobiernos tienen que responder, a pesar de que en muchos casos sus propios integrantes fueron víctimas de esas violaciones. Esa área de trabajo continuará probablemente por bastante tiempo.

Sin embargo, la situación comienza visiblemente a cambiar y la mayor parte de las quejas tiene que ver con hechos mucho más ligados al presente, con violaciones en curso que muestran que todavía la situación de nuestro continente en esta materia deja mucho que desear. Problemas de violación de derechos políticos, libertad de expresión, discriminación racial o de género, derechos de los pueblos originarios, de denegación de justicia, de abusos contra detenidos y otras, se agolpan en la Comisión, a medida que muchos latinoamericanos y caribeños ven esta como una instancia de reparación o de justicia que sienten negada en sus propios países.

Es importante verificar que en esto hay un claro progreso, en varios sentidos. Por una parte, existe una ampliación de los derechos en distintas áreas donde antes no eran reconocidos. La discriminación y el abuso contra minorías son hoy reconocidos cada vez más con el progreso del derecho internacional e interamericano y ello expande al mismo tiempo la demanda por esos derechos. Por otra parte, existe también mayor disposición de los Estados a realizar modificaciones a su legislación y ampliar la vigencia de los derechos humanos. Y finalmente, el aumento de la libertad de expresión permite el conocimiento y denuncia de muchos más casos de violaciones, que pueden llegar así a conocimiento de las organizaciones internacionales. 
Nuestro Sistema de Derechos Humanos ha sido uno de los factores en el mejoramiento de la condición general de estos derechos en el período reciente. El prestigio del Sistema, fundado en su independencia y credibilidad, ha permitido que la jurisprudencia de la Comisión y la Corte hayan tenido influencia, inter alia, en la modificación de leyes, derogación de leyes de amnistía, mejoramiento de la legislación respecto de la mujer, negociación de declaraciones contra la discriminación, mejorando considerablemente la protección de los derechos humanos de millones de personas.

Todo ello crea una demanda también de ampliación del trabajo de nuestra Comisión y nuestra Corte. La Comisión debe concentrarse no solamente en atender casos individuales, sino también en actuar, a partir de sus informes generales sobre países y temas, en una promoción más efectiva de los derechos humanos en áreas profundamente atrasadas de la política regional.

Un ejemplo muy visible está en la situación penitenciaria, forma clara y general de violación de los derechos humanos en América. La situación de las cárceles en la mayoría de nuestros países condena a muchos individuos a castigos de gran crueldad y elimina toda posibilidad de una vida normal en ellas, para no hablar de la ninguna facilidad para la rehabilitación de los reos, ni siquiera de los primerizos o menos peligrosos. En esta materia, nuestro sistema debe pasar del mero juicio de los casos que se representan, o la publicación de sus informes de relatoría, a una acción directa para mejorar las condiciones, trabajando en conjunto con los gobiernos en programas concretos de mejoramiento. Es necesario priorizar ahora también la acción de la OEA y su Sistema de Derechos Humanos en la promoción de estos derechos en las áreas en que se encuentran más afectados.

De igual modo, la Comisión debe ampliar la cooperación que ya brinda la Organización en la elaboración de instrumentos para la protección de minorías discriminadas, especialmente los pueblos indígenas y la población afrodescendiente.

4. Recursos: Todos los desafíos anteriores conducen a reexaminar las precariedades del financiamiento del Sistema Interamericano de Derechos Humanos. En la última década la cantidad de casos que se presentan ante la Comisión de Derechos Humanos se ha multiplicado varias veces, sin que haya existido un real aumento de los recursos de los que la Comisión dispone para su trabajo. La Corte Interamericana enfrenta similares limitaciones en su financiamiento. Todo ello repercute en lentitud en la atención de los casos y hace difícil, por cierto, ampliar las actividades de la Comisión y la Corte.

La centralidad de la Comisión en la vida del Sistema Interamericano, y la importancia creciente de la jurisprudencia de la Corte en el plano jurídico internacional, harían necesario un funcionamiento mucho más asiduo y un apoyo técnico de mucho mayor envergadura que el actual. Pero ello no es posible por la falta de recursos, a pesar de los esfuerzos que en esta 
materia han prestado recientemente algunos países observadores para el funcionamiento de estos órganos.

\section{$\mathrm{V}$}

Nuestra conclusión es, a pesar de todo, optimista en cuanto a la marcha del Sistema Interamericano de Derechos Humanos. Es un Sistema consolidado en su funcionamiento y sus atribuciones, con buenas relaciones con la Organización de Estados Americanos, a la cual la Comisión pertenece como órgano autónomo y con la cual, tanto ella como la Corte, mantienen un diálogo permanente y fructífero. La CIDH y la Corte son para la OEA factores de prestigio y legitimación, y una de nuestras más valiosas cartas de presentación en el hemisferio y en el mundo. La protección y promoción de los derechos humanos es uno de los rasgos esenciales del sistema democrático, proclamado en esos términos en la Carta Democrática Interamericana de 2001. Es también una de las actividades por las cuales la OEA es más reconocida y valorada. Razón de más para que todos los países miembros deban colaborar a su fortalecimiento. 